\title{
Anti-tumor necrosis factor $v$ NAR single domains reduce lethality and regulate underlying inflammatory response in a murine model of endotoxic shock
}

Rafael Bojalil ${ }^{1,2 \dagger}$, María Teresa Mata-González ${ }^{3 \dagger}$, Fausto Sánchez-Muñoz ${ }^{1}$, Yepci Yee ${ }^{1}$, Iván Argueta', Lucía Bolaños ${ }^{1}$, Luis Manuel Amezcua-Guerra', Tanya Amanda Camacho-Villegas, 4, Edna Sánchez-Castrejón ${ }^{5}$, Walter Jakob García-Ubbelohde ${ }^{3}$, Alexei Fedorovish Licea-Navarro ${ }^{5}$, Ricardo Márquez-Velasco ${ }^{1,6 *}$ and Jorge Fernando Paniagua-Solís $5^{3,7}$

\begin{abstract}
Background: In sepsis, tumor necrosis factor (TNF) is the key factor triggering respiratory burst, tissue injury and disseminated coagulation. Anti-TNF strategies based on monoclonal antibodies or $F\left(a b^{\prime}\right)_{2}$ fragments have been used in sepsis with contradictory results. Immunoglobulin new antigen receptors (IgNAR) are a unique subset of antibodies consisting of five constant (CNAR) and one variable domains (vNAR). vNAR domains are the smallest, naturally occurring, antibody-based immune recognition units, having potential use as therapy.

Our aim was to explore the impact of an anti-TNF vNAR on survival in an experimental model of endotoxic shock. Also, mRNA expression and serum protein of several inflammatory molecules were measured.

Results: Endotoxic shock was induced by lipopolysaccharide (LPS) in male Balb/c mice. Animals were treated with anti-TNF VNAR domains, F(ab') ${ }_{2}$ antibody fragments, or saline solution 15 minutes before, $2 \mathrm{~h}$ and $24 \mathrm{~h}$ after lethal dose $_{100}\left(\mathrm{LD}_{100}\right)$ LPS administration. TNF blockade with either NAR domains or F $\left(\mathrm{ab}^{\prime}\right)_{2}$ fragments were associated with lower mortality (60\% and $75 \%$, respectively) compared to $L D_{100}$. Challenge with LPS induced significant production of serum TNF and interleukins -10 and -6 at $3 \mathrm{~h}$. After that, significant reduction of IL-6 at $24 \mathrm{~h}$ (vs $3 \mathrm{~h}$ ) was shown only in the vNAR group. Nitrites level also increased in response to LPS.

In liver, TNF and IL-10 mRNA expression showed a pro-inflammatory imbalance in response to LPS. Blocking TNF was associated with a shift towards an anti-inflammatory status; however, polarization was more pronounced in animals receiving $\mathrm{F}\left(\mathrm{ab} \mathrm{b}^{\prime}\right)_{2}$ fragments than in those with vNAR therapy. With regard to IL-6, gene expression was increased at $3 \mathrm{~h}$ in all groups. TNF blockade was associated with rapid and sustained suppression of IL-6 expression, even more evident in the NAR group. Finally, expression of inducible-nitric oxide synthase (iNOS) increased in response to LPS at $3 \mathrm{~h}$, but this was decreased at $24 \mathrm{~h}$ only in the anti-TNF vNAR group.
\end{abstract}

Conclusions: Anti-TNF $v$ NAR single domains improved survival in a murine model of endotoxic shock. Protection was associated with regulation in the TNF/IL-10 balance, attenuation of IL- 6 and iNOS gene expression in the liver as well as decreased serum IL-6 concentration.

Keywords: Endotoxic shock, Sepsis, Anti-TNF, vNAR, Inflammation

\footnotetext{
* Correspondence: marquezric@hotmail.com

${ }^{\dagger}$ Equal contributors

'Department of Immunology, Instituto Nacional de Cardiología Ignacio

Chávez, Mexico City, Mexico

${ }^{6}$ Department of Health Sciences, Universidad del Valle de México, Mexico

City, Mexico

Full list of author information is available at the end of the article
} 


\section{Background}

Sepsis is a life-threatening condition which results from an exacerbated inflammatory process caused by complex interactions between the innate immune system and either bacterial sources of infection or their circulating antigens, mainly lipopolysaccharides (LPS). Circulating LPS is engaged by Toll-like receptor 4 (TLR4) on the surface of monocytes and macrophages, which in turn result in cell activation and early production of large amounts of inflammatory cytokines [1,2]. Tumor necrosis factor (TNF) plays a key role in sepsis due to its ability to trigger respiratory burst and nitric oxide production while diminishing peripheral vascular resistance, leading to disseminated intravascular coagulation and multiple organ failure [3-5].

Elucidation of pathophysiological events that underlie sepsis has led to the development of molecules targeting these pathways. Major strategies to block TNF have included the use of anti-TNF monoclonal antibodies, soluble TNF receptors with IgG chimeric protein, and anti-TNF F $\left(a b^{\prime}\right)_{2}$ fragments [6-8]. Interestingly, both the effectiveness and usefulness of each anti-TNF strategy varies among studies, often being conflictive and even contradictory. This could be partly the result of the intensity of TNF blockade as well as the tissue penetration achieved by each type of molecule.

Immunoglobulin new antigen receptors (IgNAR) are a unique subset of antibodies found in sharks. It consists of homodimers of polypeptide chains, each comprising a single variable $\left({ }_{\mathrm{V}} \mathrm{NAR}\right)$ and five constant $\left({ }_{\mathrm{C}} \mathrm{NAR}\right)$ domains. Single vNAR domains are candidates to be the smallest, naturally occurring, antibody-based immune recognition units [9]. Moreover, $\mathrm{V}$ NAR domains have been suggested as a highly effective set of molecules capable to access antigenic sites rarely targeted by conventional antibody-based strategies, positioning them as attractive candidates for therapy [10-12]. Thus, we explored the survival of mice in an experimental model of endotoxic shock, after treatment with a ${ }_{V} \mathrm{NAR}$ single domain directed against TNF.

\section{Results}

\section{Efficacy of vNAR on survival}

Survival of mice was documented for up to four days after induction of endotoxemia (Figure 1). All animals in the endotoxemic shock group died within $48 \mathrm{~h}$ following administration of $\mathrm{LD}_{100}$ LPS. In contrast, TNF blockade with either ${ }_{V}$ NAR domains or $F\left(a b^{\prime}\right)_{2}$ fragments reduced mortality as early as $24 \mathrm{~h}$ and continued until $96 \mathrm{~h}$ surveillance. $\mathrm{V}$ NAR domains were associated with lower mortality compared with $\mathrm{F}\left(\mathrm{ab}^{\prime}\right)_{2}$ fragments, although this was not significant $(40 \%$ versus $25 \%$ survival; $\mathrm{p}=0.16$ ), however both groups were significantly protected vs $\mathrm{LD}_{100}$ treatment $(\mathrm{p}<0.001$ and 0.05 respectively).

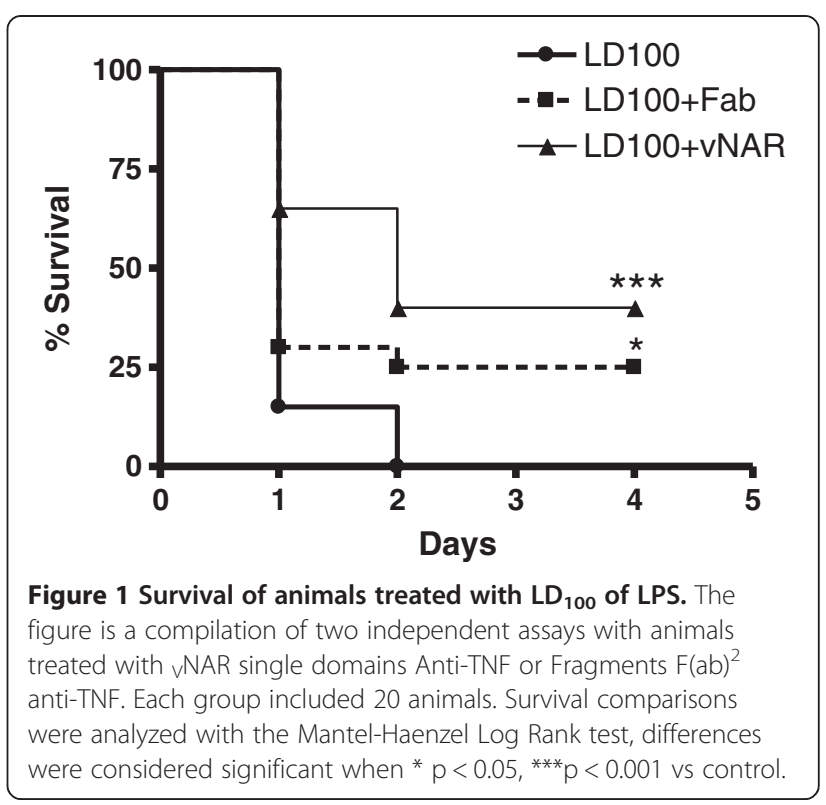

Inflammatory markers in sera

Induction of endotoxic shock produced a significant increase in the serum concentration (mean \pm standard error) of TNF at $3 \mathrm{~h}$ after LPS administration (Figure 2, panel A) in the untreated group $(435 \pm 112 \mathrm{pg} / \mathrm{mL}), \mathrm{F}\left(\mathrm{ab}^{\prime}\right)_{2}$ group $(411 \pm 79 \mathrm{pg} / \mathrm{mL})$, and ${ }_{V} N A R$ group $(947 \pm 324 \mathrm{pg} / \mathrm{mL})$ compared to animals with neither administration of LPS nor anti-TNF $(0 \mathrm{pg} / \mathrm{mL} ; \mathrm{p}<0.05$ for all comparisons $)$. Nevertheless, $F\left(a b^{\prime}\right)_{2}$ fragments induced a persistent decrease of TNF at $24 \mathrm{~h}(38 \pm 38 \mathrm{pg} / \mathrm{mL})$ and $48 \mathrm{~h}(0 \mathrm{pg} / \mathrm{mL})$, while ${ }_{\mathrm{V}} \mathrm{NAR}$ domains produced a transitory decrease at $24 \mathrm{~h}\left(0 \mathrm{pg} / \mathrm{mL} ; \mathrm{p}<0.05\right.$ vs $\left.{ }_{\mathrm{V}} \mathrm{NAR} 3 \mathrm{~h}\right)$, with a subsequent mild increase at $48 \mathrm{~h}(121 \pm 121 \mathrm{pg} / \mathrm{mL})$. Endotoxemic shock was also associated with an early raise of IL-10 (Figure 2, panel B) in untreated $(598 \pm 116 \mathrm{pg} / \mathrm{mL}$; $\mathrm{p}<0.01$ vs. animals with no endotoxemia), treated with anti-TNF $\mathrm{F}\left(\mathrm{ab}^{\prime}\right)_{2}(854 \pm 169 \mathrm{pg} / \mathrm{mL} ; \mathrm{p}<0.001)$ and with vNAR groups $(418 \pm 119 \mathrm{pg} / \mathrm{mL})$. After $24 \mathrm{~h}$ both antiTNF treatments induced a similar decline in the IL-10 concentration.

TNF/IL-10 ratio was considered to represent antagonistic inflammatory responses in endotoxic shock [13]. While a predominance of anti-inflammatory response driven by IL-10 was steadily observed in the $\mathrm{F}\left(\mathrm{ab}^{\prime}\right)_{2}$ group from $3 \mathrm{~h}$ to $48 \mathrm{~h}$ of surveillance, ${ }_{\mathrm{V}} \mathrm{NAR}$ treated animals showed a pro-inflammatory response characterized by high TNF and low IL-10 serum concentrations.

Serum concentrations (mean \pm standard error) of IL- 6 were similar at $3 \mathrm{~h}$ in all endotoxemic shock groups (Figure 2, panel C) and significantly different to those of normal group $(\mathrm{p}<0.001)$. $\mathrm{F}(\mathrm{ab})_{2}$ group showed a gradual decrement (from $13392 \pm 1749$ to $7919 \pm 1991 \mathrm{pg} / \mathrm{mL}$ at $24 \mathrm{~h}$ ), while this decline was abrupt in the ${ }_{\mathrm{V}} \mathrm{NAR}$ group 

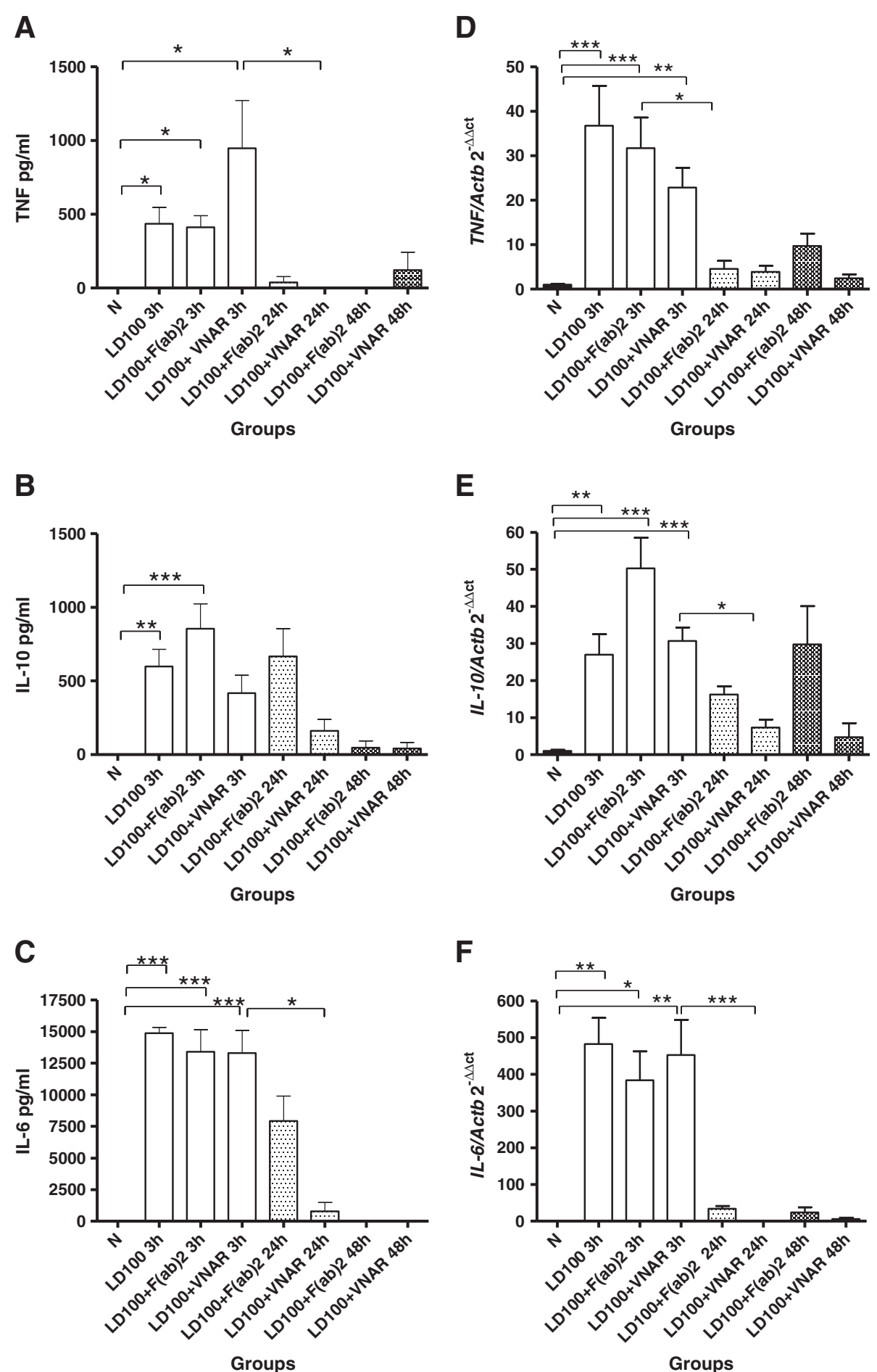

Figure 2 Production and expression of TNF, IL-6 and IL-10. Panels $\mathbf{A}, \mathbf{B}$, and $\mathbf{C}$ show levels of cytokines in serum of groups $L D_{100,} L D_{100}+$ vNAR or $L D_{100}+F(a b)^{2}$ at different times; while panels $\mathbf{D}, \mathbf{E}$, and $\mathbf{F}$ show the expression in liver of the same cytokines at same groups and times; data represent mean \pm standard error. The differences among groups were determined using a Kruskal-Wallis test and post hoc analysis using a Dunn's multiple comparison test; differences were considered significant when ${ }^{*} p<0.05,{ }^{* *} p<0.01,{ }^{* *} p<0.001$. $N=10$ animals for each group and time point. 
(from $13288 \pm 1793$ to $783 \pm 703 \mathrm{pg} / \mathrm{mL} ; \mathrm{p}<0.05$ ). IL-6 levels were undetectable at $48 \mathrm{~h}$ in all groups.

Nitrites concentration (mean \pm standard error) in sera was found to be elevated at $3 \mathrm{~h}$ in $\mathrm{LD}_{100}(1256 \pm 262$ $\mu \mathrm{M} / \mathrm{mL})(\mathrm{p}<0.05)$ and $\mathrm{F}(\mathrm{ab}) 2 \quad(1581 \pm 438 \mu \mathrm{M} / \mathrm{mL})$ $(\mathrm{p}<0.001)$ groups vs normal group $(206 \pm 74 \mu \mathrm{M} / \mathrm{mL})$, but not in ${ }_{\mathrm{V}} \mathrm{NAR}$ group $(592 \pm 144 \mu \mathrm{M} / \mathrm{mL}$ ) (Figure 3, panel A). While their concentration remained almost unchanged at $24 \mathrm{~h}(793 \pm 189 \mu \mathrm{M} / \mathrm{mL})$ in the anti-TNF ${ }_{\mathrm{V}} \mathrm{NAR}$ group, it increased around three-fold in the $\mathrm{F}(\mathrm{ab})_{2}$ fragments group (from $1581 \pm 438$ to $4000 \pm$ $657 \mu \mathrm{M} / \mathrm{mL})$.

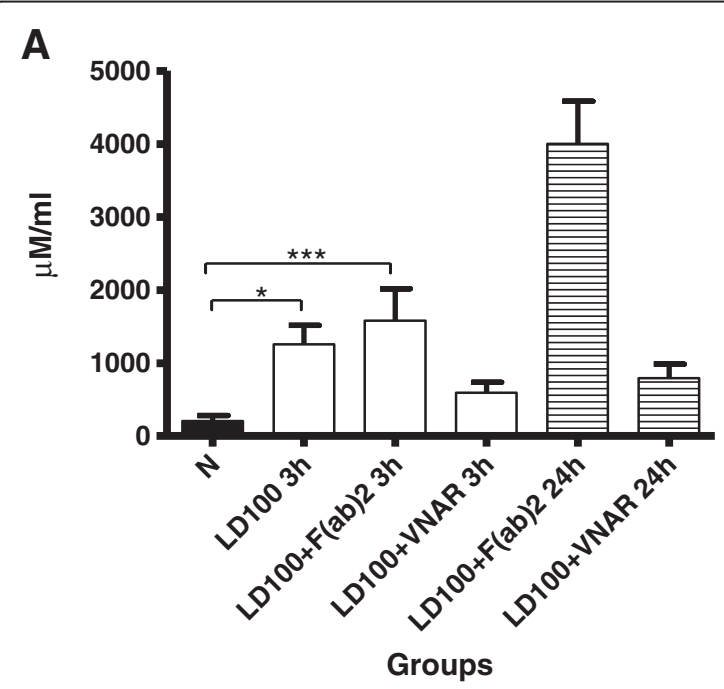

B

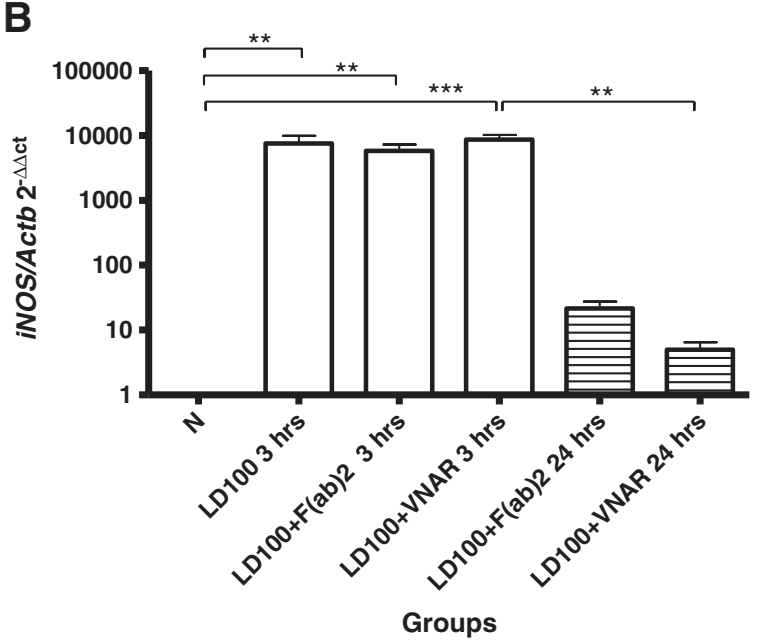

Figure 3 Production of $\mathrm{NO}_{2}^{-}$and expression of iNOS. Panel $\mathbf{A}$ shows levels of $\mathrm{NO}_{2}^{-}$in serum of groups $L D_{100}, L_{100}+$ vNAR or $L D_{100}+F(a b)^{2}$ at different times; panel $\mathbf{B}$ shows expression of iNOS in the same groups and times; data represent mean \pm standard error. Differences among groups were determined using a Kruskal-Wallis test and post hoc using a Dunn's multiple comparison test; differences were considered significant when ${ }^{*} p<0.05,{ }^{* *} p<0.01$, ${ }^{* *} \mathrm{p}<0.001 . \mathrm{N}=10$ animals for each group and time point.

\section{Liver mRNA quantification}

Relative mRNA expression of TNF and IL-10 in liver increased at $3 \mathrm{~h}$ as a result of LPS administration (Figure 2, panels $\mathrm{D}$ and $\left.\mathrm{E},{ }^{* * *} \mathrm{p}<0.01,{ }^{* * *} \mathrm{p}<0.001\right)$. However while $\mathrm{LD}_{100}$ of LPS induced a predominant pro-inflammatory response, TNF blockade with either molecule was associated with an anti-inflammatory predominance. However, subtle differences in the TNF/IL-10 balance were found, because polarization to an anti-inflammatory status was more pronounced in the animals receiving $\mathrm{F}(\mathrm{ab})_{2}$ fragments than in those with ${ }_{\mathrm{V}} \mathrm{NAR}$ therapy.

Interleukin-6 gene expression in liver increased early (3 h) after LPS challenge in all groups (Figure 2, panel F). TNF blockade was associated with rapid (24h) and sustained (48 h) suppression of IL-6 mRNA expression; however, the intensity was different according to the antiTNF strategy used. Indeed, ${ }_{\mathrm{V}} \mathrm{NAR}$ therapy showed to be more effective than $F\left(a b^{\prime}\right)_{2}$ to suppress IL-6 mRNA expression at $24 \mathrm{~h}(1.33$ versus $34.27 ; \mathrm{p}<0.05)$ and $48 \mathrm{~h}(5.69$ versus $24.20 \mathrm{p}<0.05)$ after induction of endotoxemia.

Finally, expression of mRNA inducible-nitric oxide synthase (iNOS) in liver was similar between all groups at $3 \mathrm{~h}$ (Figure 3, panel B) (from $5811 \pm 1422$ to $8560 \pm 1603$ ); at $24 \mathrm{~h}$ both anti-TNF schemes strikingly decreased iNOS mRNA expression, but only in ${ }_{\mathrm{V}} \mathrm{NAR}$ group this reduction was found to be statistically significant.

\section{Discussion}

vNAR domains are promissory antibody-based molecules because of their particular features such as low molecular weight and size, resistance to gastric $\mathrm{pH}$ and long CDR3 loop. ${ }_{\mathrm{V}} \mathrm{NAR}$ domains are currently used to neutralize bioactive molecules and viruses [11,14], as well as to perform in vitro diagnostic assays [12]. Herein, we present the first study aimed to report an anti-TNF ${ }_{\mathrm{V}} \mathrm{NAR}$ that improves survival in a murine model of endotoxic shock. Our results support a role for TNF bioactivity blockade in the treatment of sepsis, and suggest that different anti-TNF strategies may reach different survival rates through differentially attenuating inflammatory mechanisms.

In the present study, anti-TNF administration was not associated with early $(3 \mathrm{~h})$ depletion of serum TNF levels; on the contrary, TNF was detected in sera from animals in all groups. In contrast, serum TNF declined to almost undetectable levels at $24 \mathrm{~h}$ and $48 \mathrm{~h}$ after administration of either $\left.\mathrm{F}(\mathrm{ab})_{2}\right)_{2}$ fragments or ${ }_{\mathrm{V}} \mathrm{NAR}$ domains. These results are opposed to others studies showing that treatments with anti-TNF antibodies early reduce serum TNF concentration [15,16]. A possible explanation is based on the molecular weight and bioavailability of each molecule. In this context, while conventional murine monoclonal IgG antibodies (159 kD) have a serum half-life of 25 days [17], mean serum half-life of smaller 
molecules is reduced, possibly as a result of improved clearance. Indeed, $\mathrm{F}(\mathrm{ab})_{2}$ fragments $(100 \mathrm{kD})$ show a mean serum half-life of 2 hrs [18], and ${ }_{\mathrm{V}} \mathrm{NAR}$ (14 KD) single domains as little as $3 \mathrm{~min}$ to $1.5 \mathrm{hrs}$ [19].

The liver plays key physiological roles including blood filtering of toxins as well as inactivation and clearing of bacterial antigens and products [20]. Thus, the liver is a site in which early inflammatory changes in sepsis can be assessed by measuring the expression of several proand anti-inflammatory molecules [21]. Due to the size of ${ }_{\mathrm{V}} \mathrm{NAR}$ single domains, they may arrive to the liver and, possibly, deeply penetrate in hepatic tissue [22], which ultimately may result in the attenuation of inflammatory response. In our study, untreated animals with endotoxic shock showed an intense pro-inflammatory response featured by high expression of TNF and low expression of IL-10 in liver, while anti-TNF treated groups were characterized by an anti-inflammatory response featured by high expression of IL-10 and low expression of TNF.

The protective role of IL-10 in animal sepsis may be due to its antagonistic effect on the production and overall functioning of TNF [23-25]. In this way, it has been demonstrated that neutralization of IL-10 in septic animals and the induction of endotoxemic shock in IL-10 knockout animals are associated with increased tissue injury [26,27] and higher serum levels of interferon- $\gamma$ and TNF $[28,29]$. In our study, a lower anti-inflammatory TNF/IL-10 ratio was associated with the administration of ${ }_{\mathrm{V}} \mathrm{NAR}$ domains compared to $F(a b ') 2$ fragments. This could be associated with the trend for higher survival observed in the group on ${ }_{\mathrm{V}} \mathrm{NAR}$ therapy. In support to this notion, we have previously described that regulation in the IL-1 $/$ IL-10 balance is associated with protection against lethality in a sepsis model of cecal ligation and puncture [7,30]. The presence of similar results in different models of sepsis further supports that modulation of inflammation would tame tissue injury mechanisms, while full blockade of an inflammatory pathway would facilitate polarization of the immune response in either systemic inflammatory response syndrome or its counterpart, compensatory antiinflammatory response syndrome [7].

Tumor necrosis factor directly influences the production of IL-6 and iNOS [31-33] and it is conceivable that its attenuation could have regulated both gene expression and serum concentration of IL- 6 and nitric oxide (NO) in our experiments. For example, it has been reported that the administration of anti-IL-6 antibodies improves survival in sepsis [34,35]; while TNF blockade inhibits hepatic expression of iNOS and nitrotyrosine in mice with endotoxic shock [36].

In addition, protection of liver seems to be critical to obtain beneficial outcomes in sepsis. In a recent study performed in rats with polymicrobial sepsis, treatment with hyperoncotic albumin attenuates hepatic injury in association with reduced plasma levels of IL-1 $\beta$, IL-6, liver enzymes, and $\mathrm{O}_{2}^{-}$concentrations [37]. These results support anti-TNF ${ }_{\mathrm{V}} \mathrm{NAR}$ domains as an alternative approach in the treatment of sepsis, due to its attenuating effects on the inflammatory response showed in liver; however these must be further studied in more aggressive models such as the polymicrobial sepsis induced by cecal ligation and puncture. Related to the latter study, a recent rat gut model of indomethacin-induced jejunoileitis showed that anti-TNF- $\alpha$ monoclonal antibody reduced iNOS expression and IL-1 beta, the latter two thought to be key mediators of inflammatory bowel disease [38].

\section{Conclusions}

Anti-TNF ${ }_{\mathrm{V}} \mathrm{NAR}$ single domains are a novel strategy useful to improve survival in a murine model of endotoxic shock, with efficacy similar to that observed with the use of anti-TNF F(ab')2 fragments. Protection against lethality was associated with regulation in the TNF/IL-10 inflammatory balance, attenuation of IL-6 and iNOS liver expression, and decreased IL- 6 serum concentration.

\section{Methods}

\section{Isolation of anti-TNF vNAR single domains}

Isolation of anti-TNF ${ }_{V}$ NAR domains was performed as previously described $[39,40]$. In brief, a specimen of horn shark Heterodontus francisci was repeatedly immunized (intravenous route) with human recombinant TNF (Peprotech Inc, Connecticut USA). After immunization, RNA from the spleen was obtained and used to amplify variable genes through polymerase chain reaction (PCR), and libraries were generated. A specific clone was obtained by phage display technique and cultures of Pichia pastoris were used to express it, in accordance with the Easy Select Pichia Expression Manual (Invitrogen, USA); pPICZ $\alpha$ Avector and X-33 strain were used. vNAR single domains were isolated and purified in the Centro de Investigación Científica y de Educación Superior de Ensenada (Mexico).

\section{Induction of murine endotoxic shock and treatment schedule}

Protocol was approved by the ethics committee at the Instituto Nacional de Cardiología Ignacio Chávez (Protocol number 11-726). Male Balb/c mice, classified as an inbred based on 20 or more successive brother-sister matings [41], 8-12 weeks old were housed under standard laboratory conditions with food and water ad libitum (UAM-Xochimilco, Mexico City, Mexico). Initially, independent experiments were performed to investigate the Lethal Dose $100\left(\mathrm{LD}_{100}\right)$, which was found to be $20 \mathrm{mg} / \mathrm{kg}$ of LPS serotype O55:B5 (Sigma-Aldrich, St. Louis, MO) diluted in $100 \mu \mathrm{L} 0.9 \%$ saline solution, 
administered by intraperitoneal (IP) injection in a single dose. Similarly, a pilot assay was performed to investigate the dose of anti-TNF vNAR domains useful to improve survival in the murine model of endotoxemic shock, doses of $0.01,0.1$ and $1 \mathrm{mg} / \mathrm{kg}$ of VNAR antiTNF were tested, the latter dose was the only one that induced protection. To compare active treatment with anti-TNF ${ }_{V}$ NAR domains, we used anti-TNF $F\left(a^{\prime}\right)_{2}$ antibody fragments (Laboratorios Silanes, Mexico City, MX). We used the same dose of the latter antibody $(1 \mathrm{mg} / \mathrm{kg})$ since it had previously shown protective activity in the cecal ligation and puncture model.

Mice (20 per group) were allocated in groups to receive (A) $\mathrm{LD}_{100} \mathrm{LPS}$ in $100 \mu \mathrm{L} 0.9 \%$ saline solution by IP injection, these mice also received $100 \mu \mathrm{l}$ of $0.9 \%$ saline solution by IP injection, 15 minutes before as well as at 2 and $24 \mathrm{~h}$ after $\mathrm{LD}_{100}$ LPS was administrated; (B) $1 \mathrm{mg} / \mathrm{kg}$ antiTNF VNAR domains diluted in $100 \mu \mathrm{l} 0.9 \%$ saline solution by IP injection, 15 minutes before as well as at 2 and $24 \mathrm{~h}$ after $\mathrm{LD}_{100}$ LPS was administrated; (C) $1 \mathrm{mg} / \mathrm{kg}$ anti-TNF $\mathrm{F}\left(\mathrm{ab}^{\prime}\right)^{2}$ antibody fragments diluted in $100 \mu \mathrm{L} 0.9 \%$ saline solution by IP injection administrated in a similar time schedule than ${ }_{\mathrm{V}} \mathrm{NAR}$ domains; (D) $100 \mu \mathrm{l}$ 0.9\% saline solution IP in the same time schedule as the other groups; these mice received neither LPS nor anti-TNF treatment.

\section{Measurement of serum markers}

Using another batch of mice, blood from 10 anesthetized animals for each group and time was obtained by cardiac puncture at 3, 24 and $48 \mathrm{~h}$ after induction of endotoxemia. Serum TNF, IL-6 and IL-10 concentrations were measured by enzyme-linked immunosorbent assays (R\&D Systems, Minneapolis, MN). In addition, non-hemolysed serum was used to measure nitrites $\left(\mathrm{NO}_{2}^{-}\right)$by means of a Griess reagent system (Promega Corp, Madison, USA). All assays were performed according to manufacturer.

\section{Liver mRNA quantification by RT-qPCR}

Ten animals per group and time were sacrificed at 3, 24 or $48 \mathrm{~h}$ after LPS administration and liver tissue was immediately frozen and stored at $-70^{\circ} \mathrm{C}$. One-hundred milligrams from each liver were homogenized using Tri Reagent (Sigma-Aldrich). RNA integrity was assessed by agarose gel stained with ethidium bromide and purity was determined by spectrophotometer $(260 / 280>1.8) ; 2$ micrograms of total RNA were retro-transcribed using random primers in a $20 \mu \mathrm{l}$ reaction with the Transcriptor First cDNA synthesis kit (Roche Applied Science, Indianapolis, USA). One microliter of cDNA was amplified by qPCR using the LightCycler 2.0 with LightCyclerTaqMan Master Mix (Roche) and PCR primers in combination with LNA hydrolysis probes designed with the probe finder software v. 2.45 from the Universal Probe Library Mouse Set (Roche).
PCR was performed using the following primers: Inducible nitric oxide synthase 2 (NM_010927.3), forward 5' gggctgtcacggagatca-' 3 , reverse 5 '-ccatgatggtcacattctgc-' 3 ; IL-6 (NM_031168.1), forward 5'-gctaccaaactggatataa tcagga-'3, reverse 5 '-ccaggtagctatggtactccagaa-'3; IL10 (NM_007393.3), forward 5' -cagagccacatgctcctaga-'3, reverse 5 ' -gtccagctggtcctttgttt-' 3 ; TNF (NM_013693.2), forward 5 ' -tcttctcattcctgcttgtgg-' 3 , reverse 5 ' -ggtctgggc catagaactga-'3; and Actb (NM_007393.3), forward 5' ctaaggccaaccgtgaaaag-' 3 , reverse 5 '-accagaggcatacaggg aca-' 3 as a constitutive gen.

Relative expression of each gene was calculated according to $2^{-\Delta \Delta C t}$. Assays were tested for linearity and reproducibility (variation coefficients $<10 \%$ ).

\section{Statistical analyses}

Results are expressed as proportions or mean \pm standard deviation. Comparison of survival curves was performed using the Mantel-Haenzel log-rank test. Differences between two independent groups were calculated by MannWhitney tests, while those comparisons including more than two groups were performed by the Kruskal-Wallis test (Dunn's post test). All analyses were 2-tailed and a $\mathrm{p}<0.05$ value was used for significance. The GraphPad Prism v 4.02 statistical software (GraphPad Inc, San Diego, CA) was used.

\section{Abbreviations}

IgNAR: Immunoglobulin new antigen receptors; IL: Interleukin; iNOS: Inducible nitric oxide synthase; $L_{10}$ : Lethal dose 100;

LPS: Lipopolysaccharide; TLR4: Toll-like receptor 4; TNF: Tumor necrosis factor; NAR: Single variable domain.

\section{Competing interests}

FS-M, YY, IA, LB and LMA-G declare they have no competing interest. RM-V and $\mathrm{RB}$ received a research support by Laboratorios Silanes-Fundación Mexicana para la Salud. MTM-G, WJG-U and JFP-S were employed by Laboratorios Silanes at the time of the manuscript was written. TAC-V, ES-C and AFL-N received a grant support by Laboratorios Silanes. Funding source was provided by Laboratorios Silanes and Fundación Mexicana para la Salud with the support fund number 471.

\section{Authors' contributions}

$R M-V$ and RB contributed to the conception and design of the study, the interpretation of data and the elaboration of the manuscript. RM-V, BL, YY, Al, FS-M and LMA-G contributed with the development of experiments and in the interpretation of data. TAC-V, ES-C, WJG-U, AFL-N contributed in the isolation and production of anti-TNF VNAR. MTM-G, WJG-U, JFP-S contributed in the isolation, characterization, and production of anti-TNF ${ }_{\text {NNAR. All }}$ authors reviewed and approved the final manuscript.

\section{Acknowledgments}

This study was supported by Laboratorios Silanes, S. A. de C. V. and Fundación Mexicana para la Salud A. C. Mexico City, Mexico.

\section{Author details}

'Department of Immunology, Instituto Nacional de Cardiología Ignacio Chávez, Mexico City, Mexico. ${ }^{2}$ Department of Health Care, Universidad Autónoma Metropolitana-Xochimilco, Mexico City, Mexico. ${ }^{3}$ Laboratorios Silanes, S. A. de C. V. Amores 1304, Col del Valle, 03100, Mexico City, Mexico, ${ }^{4}$ Marine Science Faculty, Universidad Autónoma de Baja California, Km. 103 Carretera Tijuana-Ensenada, Ensenada, Mexico. ${ }^{5}$ Marine Biotechnology Department, Centro de Investigación Científica y de Educación Superior de 
Ensenada (CICESE), Ensenada, Mexico. ${ }^{6}$ Department of Health Sciences, Universidad del Valle de México, Mexico City, Mexico. ${ }^{7}$ Current Address (JFP-S): Teraclon IDF; Parque Científico de Madrid, Tres Cantos, Madrid, España.

Received: 3 September 2012 Accepted: 11 March 2013 Published: 2 April 2013

\section{References}

1. López-Bojórquez LN, Zentella-Dehesa A, Reyes-Terán G: Molecular mechanisms involved in the pathogenesis of septic shock. Arch Med Res 2004, 35:465-479.

2. Tetta C, Fonsato V, Ronco C, Camussi G: Recent insights into pathogenesis of severe sepsis. Crit Care Resusc 2005, 7:32-39.

3. Macdonald J, Galley HF, Webster NR: Oxidative stress gene expression in sepsis. Br J Anaesth 2003, 90:221-232.

4. Fujii E, Yoshioka T, Ishida H, Irie K, Muraki T: Evaluation of iNOS- dependent and independent mechanisms of the microvascular permeability change induced by lipopolysaccharide. Br J Pharmacol 2000, 130:90-94.

5. Zeerleder S, Hack E, Wuillemin WA: Disseminated intravascular coagulation in sepsis. Chest 2005, 128:2864-2875.

6. Remick D, Manohar P, Bolgos G, Rodríguez J, Moldawer L, Wollenberg G Blockade of tumor necrosis factor reduces lipopolysaccharide lethality, but not the lethality of cecal ligation and puncture. Shock 1995, 4:89-95

7. Márquez-Velasco R, Bojalii R, Buelna A, Flores-Guzmán F, Estevez-Ramirez J, Laguna J, et al: Anti-tumor necrosis factor alpha $F\left(a b^{\prime}\right) 2$ antibody fragments protect in murine polymicrobial sepsis: concentration and early intervention are fundamental to the outcome. Inflamm Res 2006, 5:378-384.

8. Karima R, Matsumoto S, Higashi H, Matsushima K: The molecular pathogenesis of endotoxic shock and organ failure. Mol Med Today 1999, 5:123-132

9. Juarez K, Dubberke G, Lugo P, Koch-Nolte F, Buck F, Haag F, Licea A Monoclonal antibodies for the identification and purification of VNAR domains and IgNAR immunoglobulins from the horn shark Heterodontus francisci. Hybridoma (Larchmt) 2011, 30:323-329.

10. Nuttall S, Humberstone K, Krishnan U, Carmichael J, Doughty L, Hattarki M, et al: Selection and affinity maturation of IgNAR variable domains targeting Plasmodium falciparum AMA1. Proteins 2004, 55:187-197.

11. Henderson KA, Strelstov VA, Coley AM, Dolezal O, Hudson PJ, Batchelor AH, et al Structure of an VNAR-AMA1 complex: targeting a conserved hydrophobic cleft broadens malaria strain recognition. Structure 2007, 15:1452-1466.

12. Liu JL, Anderson GP, Delehanty JB, Baumann R, Hayhurst A, Goldman ER: Selection of cholera toxin specific VNAR single- domain antibodies from a naïve shark library. Selection of cholera toxin specific VNAR single-domain antibodies from a naive shark library. Mol Immunol 2007, 44:1775-83.

13. Mengozzi M, Ghezzi P: Cytokine down-regulation in endotoxin tolerance. Eur Cytokine Netw 1993, 4:89-98.

14. Walsh R, Nuttall S, Revill P, Colledge D, Cabuang L, Soppe S, Dolezal O, et al: Targeting the hepatitis $B$ virus precore antigen with a novel VNAR single variable domain intrabody. Virology 2011, 41:132-141.

15. Evans T, Carpenter A, Silva A, Cohen J: Differentitial effects of monoclonal antibodies to tumor necrosis factor and gamma interferon on induction of hepatic nitric oxide synthase in experimental gram-negative sepsis. Infect Immun 1992, 60:4133-4139.

16. Karzai W, Cui X, Mehlton B, Straube E, Hartung T, Gerstenberger E, et al: Protection with antibody to tumor necrosis factor differs with similarly lethal Escherichia coli versus Staphylococcus aureus pneumonia in rats. Anesthesiology 2003, 99:81-89.

17. Wang W, Wang EQ, Balthasar JP: Monoclonal Antibody Pharmacokinetics and Pharmacodynamics. Clin Pharmacol Ther 2008, 84:548-558.

18. Holliger P, Hudson P: Engineered antibody fragments and the rise of single domains. Nat Biotechnol 2005, 23:1126-1136.

19. Cortez-Retamozo V, Lauwereys M, Hassanzadeh G, Gobert M, Conrath K Muyldermans $S$, et al: Efficient tumor targeting by single-domain antibody fragments of camels. Int J Cancer 2002, 98:456-462

20. Dhainaut JF, Marin N, Mignon A, Vinsonneau A: Hepatic response to sepsis: Interactions between coagulation and inflammatory processes. Crit Care Med 2001, 29:S42-S47.

21. Wu RQ, Xu YX, Song XH, Chen $\sqcup$, Meng XJ: Adhesion molecule and proinflammatory cytokine gene expression in hepatic sinusoidal endothelial cells following cecal ligation and puncture. World J Gastroenterol 2001, 7:128-130.
22. Wesolowski J, Alzogaray V, Reyelt J, Unger M, Juarez K, Urrutia M, et al: Single domain antibodies: promising experimental and therapeutic tools in infection and immunity. Med Microbiol Immunol 2009, 198:157-174.

23. Gérard C, Bruyns C, Marchant A, Abramowicz D, Vandenabeele P, Delvaux A, et al: Interleukin 10 reduces the release of tumor necrosis factor and prevents lethality in experimental endotoxemia. J Exp Med 1993, 177:547-550.

24. Kato T, Murata A, Ishida $H$, Toda $H$, Tanaka $N$, Hayashida $H$, et al: Interleukin 10 reduces mortality from severe peritonitis in mice. Antimicrob Agents Chemother 1995, 39:1336-1340.

25. Latifi SQ, O'Riordan MA, Levine AD: Interleukin 10 controls the onset of irreversible septic shock. Infect Immun 2002, 70:4441-4446.

26. Lu J, Sadri N, Schneider RJ: Endotoxic shock in AUF1 knockout mice mediated by failure to degrade proinflammatory cytokine mRNAs. Genes Dev 2006, 20:3174-3184.

27. ter Steege JC, van de Ven WC, Forget P, Buurman WA: Regulation of lipopolysaccharide-induced NO synthase expression in the major organs in a mouse model. The roles of endogenous interferon- $\gamma$, tumor necrosis factor-alpha; and interleukin-10. Eur Cytokine Netw 2000, 11:39-46.

28. Berg DJ, Kühn R, Rajewsky K, Müller W, Menon S, Davidson N, et al: Interleukin-10 is a central regulator of the response to LPS in murine models models of endotoxic shock and the Schwartzman reaction but not endotoxin tolerance. J Clin Invest 1995, 96:2339-2347.

29. Marchant A, Bruyns C, Vandenabeele P, Ducarme M, Gérard C, Delvaux A, et al: Interleukin-10 controls interferon-gamma and tumor necrosis factor production during experimental endotoxemia. Eur J Immunol 1994, 24:1167-1171.

30. Márquez-Velasco R, Martínez-Velázquez AX, Amezcua-Guerra LM, FloresGuzmán F, Díaz-Quiñonez A, Massó F, et al: Enhanced survival from CLPinduced sepsis following late administration of low doses of anti-IFNYF (ab')2 antibody fragments. Inflamm Res 2011, 60:947-953.

31. Cesaris P, Starace D, Riccioli A, Padula F, Filipinu A, Ziparo E: Tumor necrosis factor-a induces interleukin- 6 production and integrin ligand expression by distinct transduction pathways. J Biol Chem 1998, 273:7566-7571.

32. Vincent $J$, Zhang $H$, Szabo C, Preiser JC: Effects of nitric oxide in septic shock. Am J Respir Crit Care Med 2000, 161:1781-1785.

33. Bekker L, Freeman S, Murray PJ, Ryffel B, Kaplan G: TNF-a controls intracellular Mycobacterial growth by both inducible nitric oxide synthase-dependent and inducible nitric oxide synthase-independent pathways. J Immunol 2001, 166:6728-6734.

34. Riedemann NC, Neff TA, Guo RF, Bernacki KD, Laudes IJ, Sarma JV, et al: Protective effects of IL-6 blockade in sepsis are liked to reduced C5a receptor expression. J Immunol 2003, 170:503-507.

35. Liang B, Gardner D, Griswold D, Song X: Protection against lipopolysaccharide-induced death by an anti-IL-6 monoclonal antibody. Am J Immunol 2007, 3:4-9.

36. Morikawa A, Kato Y, Sugiyama T, Koide N, Chakravortty D, Yoshida T, Yokochi T: Role of nitric oxide in lipopolysaccharide-induced hepatic injury in D-galactosamine-sensitized mice as an experimental endotoxic shock model. Infect Immun 1999, 67:1018-1024.

37. Tsao CM, Huang HC, Chen ZF, Liaw WJ, Lue WM, Chen A, Chen SJ WUCC: Beneficial effects of hyperoncotic albumin on liver injury and survival in peritonitis-induced sepsis rats. Shock 2011, 35:210-216.

38. Nandi J, Saud B, Zinkievich JM, Yang ZJ, Levine RA: TNF-alpha modulate iNOS expression in an experimental rat model of indomethacin-induced jejunoileitis. Mol Cell Biochem 2010, 336:17-24.

39. Minsky A, Summers RG, Knowles JR: Secretion of beta lactamase into the periplasm of Escherichia coli: evidence for a distinct release step associated with a conformational change. Proc Natl Acad Sci USA 1986, 83:4180-4184

40. Barbas CF, Burton DR, Scott JK: Phage Display: A Laboratory Manual. New York: Cold Spring Harbor Laboratory Press, Cold Spring Harbor; 2001

41. Hilgers J, van Nie R, Ivanyi D, Hilkens J, Michalides R, de Moes J, Poort-Keesom $R$, Kroezen $V$, von Deimling O, Kominami R, Holmes R: Genetic differences in BALB/c sublines. Curr Top Microbiol Immunol 1985, 122:19-30.

\section{doi:10.1186/1471-2172-14-17}

Cite this article as: Bojalil et al: Anti-tumor necrosis factor yNAR single domains reduce lethality and regulate underlying inflammatory response in a murine model of endotoxic shock. BMC Immunology 2013 14:17. 